\title{
Physicochemical Properties of Organic Liquid Fertilizer with Oil Cake and Rice Bran as Affected by Microorganism and the Ratio of Molasses
}

\author{
Nan-Hee An*, Yong-Ki Kim, Jung-Rai Cho, Hyeong-Jin Jee, Byung-Mo Lee, \\ Jong-Chul Yoon, and Ji-Won Choi \\ National Academy of Agricultural Science, RDA, Suwon 441-707, Korea
}

(Received: October 10 2013, Accepted: November 29 2013)

The study was conducted to investigate changes in the characteristics of inorganic components during fermenting process of organic liquid fertilizers according to the type and ratio of microorganism and the amount of molasses when producing organic liquid fertilizers using sesame oil cake and rice bran. To select appropriate microorganisms, liquid fertilizers were produced through a 90-day fermentation process by adding mag-ggeo-li, yogurt, dried yeast, and leaf mold. The $\mathrm{pH}$ in liquid fertilizer was decreased, and then increased in all microorganism samples except the mag-ggeo-li sample. The EC was rapidly increased in all samples until the $10^{\text {th }}$ days after production, and showed no changes after the $60^{\text {th }}$ days in dried yeast and after the $30^{\text {th }}$ days in the other samples. The concentration of $\mathrm{NH}_{4}-\mathrm{N}$ was generally increased with time. The concentration of $\mathrm{P}_{2} \mathrm{O}_{5}$ was rapidly increased until the $10^{\text {th }}$ days after production and was maintained at about $1 \%$ regardless of the type of microorganism. In terms of the characteristics of liquid fertilizers according to the ratio of selected dried yeast, the $\mathrm{pH}$ was decreased until the $30^{\text {th }}$ days after producing the liquid fertilizers, and then was increased regardless of the ratio of dried yeast. The EC was increased with time and showed no differences depending on the amount of dried yeast. The concentration of $\mathrm{NH}_{4}-\mathrm{N}$ was increased with time and in proportion to the amount of dried yeast. In terms of the characteristics of liquid fertilizers according to the ratio of molasses, the $\mathrm{pH}$ was decreased with increasing the molasses. The $\mathrm{EC}$ and concentration of $\mathrm{P}_{2} \mathrm{O}_{5}$ were no differences according to the amount of molasses. When $3 \%$ molasses was added, the content of $\mathrm{NH}_{4}-\mathrm{N}$ was $2.6 \mathrm{mg} \mathrm{L}^{-1}$ at the beginning and was at $3,025 \mathrm{mg} \mathrm{L}^{-1}$ on the $90^{\text {th }}$ days.

Key words: Organic liquid fertilizer, Oil cake, Rice bran, Microorganism, Molasses
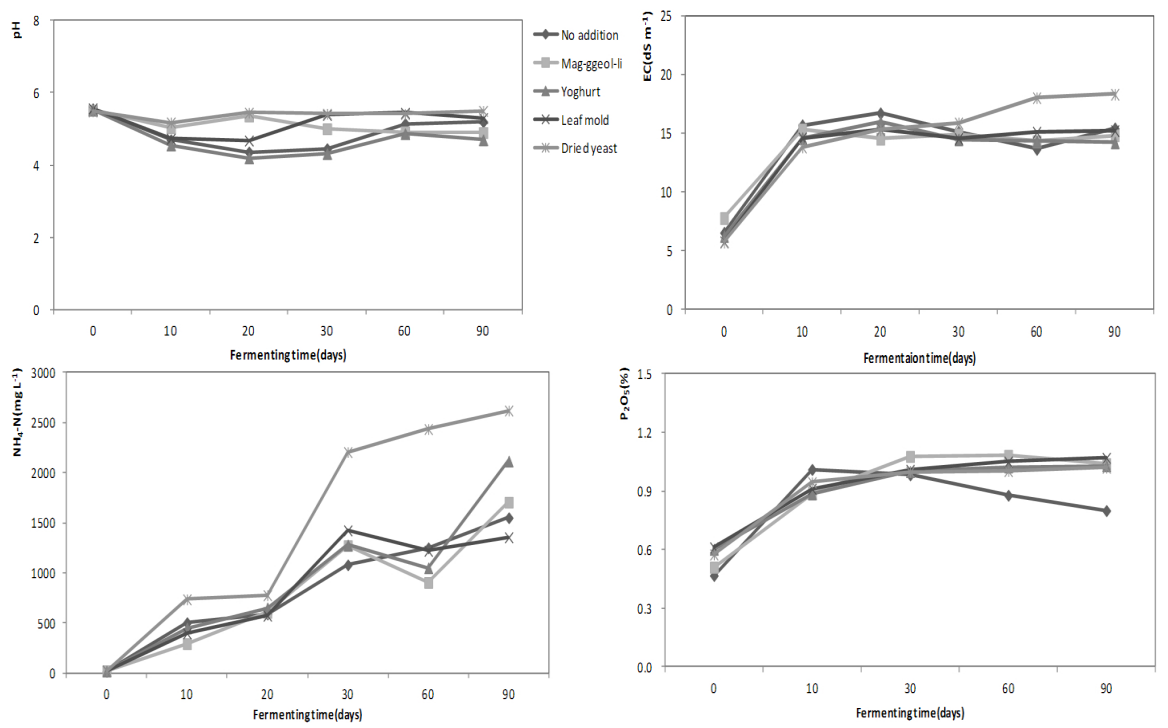

Change of pH, EC, NH4-N and $\mathrm{P}_{2} \mathrm{O}_{5}$ contents of liquid fertilizers with oil cake and rice bran as fermented by different microorganisms.

\footnotetext{
*Corresponding author : Phone: +82312900553, Fax: +82312900507, E-mail: nanhee79@korea.kr

${ }^{\S}$ Acknowledgement: This study was carried out with the support of "Research Program for Agricultural Science \& Technology Development (Project No. PJ008560022013)"
} 


\section{Introduction}

작물 생육을 위한 양분은 다양한 경로를 통해 농경지로 유입되는데 가능한 한 지역 내 양분자원 (녹비, 작물잔사, 퇴비 등)을 활용하여 자원순환을 극대화하는 것이 바람직하 다. 작물생산을 위한 양분관리는 적절한 시점에 작물에 필 요한 양분을 공급하며 장기적으로는 양분용탈이나 환경오 염을 피하기 위해 양분의 유입 및 유출에 관한 균형을 유지 하는 것이 중요하다 (RDA, 2010). 유기농업에서는 녹비, 윤 작재배, 유기자원의 활용 및 토양에 축척된 유기물로부터 양분공급을 원칙으로 하며 양분이 주변 환경으로 유출되었 을 때나 식물 생장에 따라 경우 토양에 추가적인 보충이 필 요하다. 웃거름용으로 활용되는 액비는 식물이 필요로 하는 양분을 공급하는 효과 (Park et al., 2001) 외에도 토양에 유 익한 미생물을 활성화하기도 하는데 액비에서 공급하는 양 분과 미생물 발효산물은 뿌리보호, 발근촉진 등 작물생육에 다양한 측면에서 이로운 효과를 나타낸다고 알려져 있다 (Kai et al., 1990; Elad and Shtienberg, 1994). 그동안 우 리나라에서 액비에 대한 연구는 가축분뇨 액비에 대한 제조 특성과 벼, 채소류 등에 대한 시용효과 등으로 이루어졌다 (Kim et al.,2001; Park et al., 2001; Jeon et al., 2003; Lee et al., 2006). 유기질 재료의 액비화 연구는 계분, 골 분, 쌀겨 등의 액비화 과정중 화학성 변화 및 상추에 대한 시용 효과를 연구하였다 (Joo et al., 2001). Choi et al. (2008)은 유기농 고추 재배를 위한 유기자원 선발 및 시용 효과 연구에서 액비처리로 안정적인 생육 및 수량 확보가 가능한 사실을 밝혔고, An et al. (2011)은 혈분을 이용한 액 비의 특성에 관한 연구결과를 각각 보고하였다.

실제로 유기재배 농가에서는 깻묵, 쌀겨, 골분 등 다양한 유기질 재료를 이용한 액비가 자가 제조하여 활용되고 있지 만 액비의 제조방법이나 화학적, 미생물학적 특성에 대한 체계적인 연구가 미흡한 실정이다. 따라서 본 연구는 참깻 묵과 쌀겨를 이용한 유기 액비 제조 시 발효 미생물 및 당밀 첨가량에 따른 액비의 특성을 구명하고자 수행하였다.

\section{Materials and Methods}

액비 제조에 사용된 유기질 재료는 질소원으로 참깻묵, 인산원으로 쌀겨를 사용하였으며 재료의 특성은 Table 1 과 같다. 참깻묵은 질소와 인 (P)함량이 각각 $7.0 \%, 2.8 \%$ 였고
쌀겨는 $2.5 \%, 4.2 \%$ 이었다. 참깻묵과 쌀겨의 배합비율은 깻 묵을 20\%, 쌀겨를 $10 \%$ 로 하였으며 2012년 4월에 제조하여 상온에서 혐기조건으로 발효하였다. 액비 제조 과정 중 유 기자원의 분해를 촉진시키기 위한 발효미생물을 선발하기 위하여 막걸리, 요구르트, 건조효모, 부엽토를 첨가하였으 며 선발된 미생물의 첨가량을 결정하기 위해 $0 \%, 1 \%, 2 \%$, 그리고 $3 \%(\mathrm{w} / \mathrm{v})$ 을 첨가하여 액비의 특성을 비교하였다. 발 효미생물들의 탄소원으로 당밀이 사용되었으며 첨가량에 따른 액비의 특성조사 시험에서는 당밀을 각각 $0 \%, 1 \%, 3 \%$, 그리고 $5 \%(\mathrm{w} / \mathrm{v})$ 첨가하여 발효시켰다. 액비제조 당일부터 30 일, 60 일, 90 일에 액비 시료를 채취하여 분석시료로 사용 하였다. 무기성분은 시료 $10 \mathrm{~mL}$ 을 삼각플라스크에 넣고 $\mathrm{H}_{2} \mathrm{SO}_{4}$ $5 \mathrm{~mL}$ 를 첨가한 다음 습식 분해하여 토양식물체 분석법에 준하여 분석하였다 (RDA, 2000). 무기태 질소는 여과 후 희석 하여 FIA (QuikChem 8500 Series 2, HACH, USA)로 측정하였 고 유효인산 함량은 spectrophotometer (UV-2450, SHIMADSU, JAPAN), 양이온은 ICP (Integra XL Dual, Sciencetific Equipment) 로 측정하였다.

\section{Results and Discussion}

발효 미생물에 따른 액비 특성 비교 막걸리, 요구르 트, 건조효모, 부엽토를 $3 \%$ 첨가하여 발효 기간 동안 액비 의 $\mathrm{pH}, \mathrm{EC}$, 무기태 $\left(\mathrm{NH}_{4}-\mathrm{N}\right)$ 질소, 인산 함량을 분석한 결과 는 Fig. 1 과 같았다. $\mathrm{pH}$ 는 액비 제조 당일에는 5.5 5.6이었 으며 발효기간 동안 낮아졌다 증가하는 경향 이었지만 막걸 리 첨가구의 경우 제조 20 일 이후부터 낮아지는 경향을 보 였다. 미생물 종류에 따른 $\mathrm{pH}$ 변화는 요구르트 첨가구 에서 는 제조 30 일 차에 4.3 로 가장 낮았고 이후 증가하여 60 일 차에서 90 일차까지 4.9 로 큰 변화가 없었다. 부엽토 첨가구 의 경우 5.6 에서 제조 20 일 경과 후 4.7 로 감소하였으며 이 후 증가하여 30 일차부터 5.4로 차이가 없었는데 무첨가구 보다 높았다. 또한 건조효모 첨가구의 경우 제조 10 일차에 5.2 로 약간 낮아졌다가 증가하여 20일 후부터 5.4로 변화가 거의 없었다. 그러나 막걸리 첨가구의 경우 발효 기간 동안 5.5 에서 4.9 로 감소하였다. 이러한 결과는 유기질 비료를 발효시켰을 때 $\mathrm{pH}$ 는 액비원료와 무관하게 초기에 낮아지다 가 서서히 증가한다는 결과 (Lee et al., 2011)와 호기적인 조건에서는 점차 높아지고 혐기조건에서는 유기산의 증가 로 낮아졌다는 결과 (Jung et al., 1998; Lee et al., 2007)

Table 1. Chemical properties of materials used for producing organic liquid fertilizer.

\begin{tabular}{|c|c|c|c|c|c|c|c|}
\hline Material & $\mathrm{T}-\mathrm{C}$ & $\mathrm{T}-\mathrm{N}$ & $\mathrm{P}_{2} \mathrm{O}_{5}$ & $\mathrm{~K}_{2} \mathrm{O}$ & $\mathrm{CaO}$ & $\mathrm{MgO}$ & $\mathrm{C} / \mathrm{N}$ \\
\hline & --- & 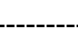 & ---- & $\mathrm{g} \mathrm{kg}^{-1}$ & 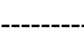 & & ---- \\
\hline Sesame oil cake & 46.5 & 7.0 & 2.8 & 1.4 & 3.0 & 1.3 & 6.7 \\
\hline Rice bran & 46.2 & 2.5 & 4.2 & 4.5 & 0.2 & 2.9 & 18.7 \\
\hline
\end{tabular}



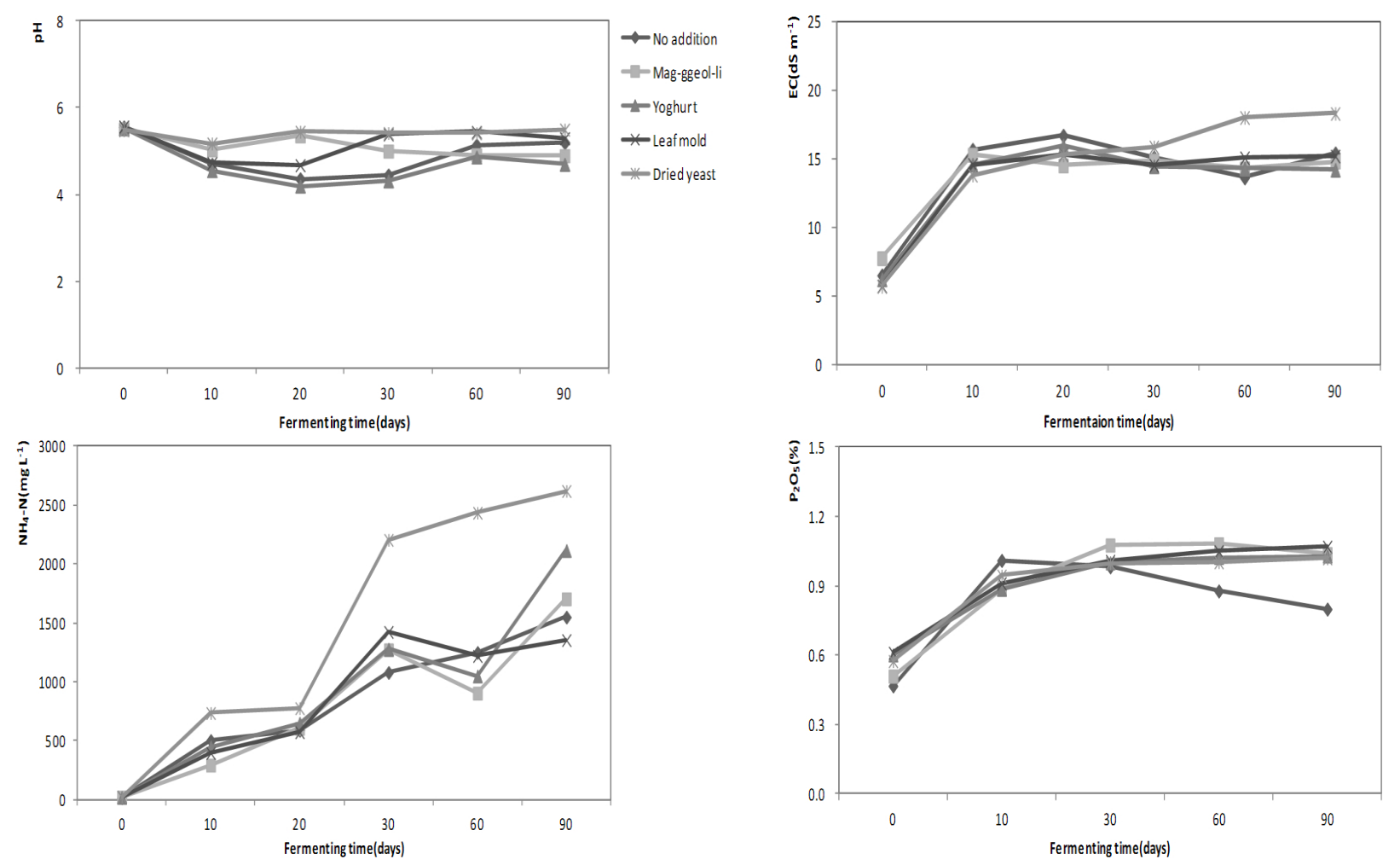

Fig. 1. Change of $\mathrm{pH}, \mathrm{EC}, \mathrm{NH}_{4}-\mathrm{N}$ and $\mathrm{P}_{2} \mathrm{O}_{5}$ contents of liquid fertilizers femented with different microorganisms.

와 일치하였다.

$\mathrm{EC}$ 는 제조 후 10 일차까지 급격히 증가하다가 건조효모 첨가구는 60 일, 다른 미생물 첨가구에서는 30 일 이후 변화 가 없었다. $\mathrm{EC}$ 의 변화 요인은 $\mathrm{H}^{+}, \mathrm{OH}^{-}, \mathrm{HCO}_{3}{ }^{-}, \mathrm{NH}_{4}{ }^{+}, \mathrm{NO}_{3}{ }^{-}$ 등이며 이들 이온의 조성에 따라 $\mathrm{EC}$ 의 값이 결정된다는 보 고와 같이 (Jeong et al, 1997) 액비화 과정에서 $\mathrm{EC}$ 는 유기 물의 무기화 작용으로 인하여 증가한 것으로 판단되었다. $\mathrm{NH}_{4}-\mathrm{N}$ 농도는 발효가 진행될수록 증가하는 경향이었으며 건조효모 > 요구르트 > 막걸리 > 무첨가 >부엽토 첨가 순으 로 높았다. $\mathrm{NO}_{3}-\mathrm{N}$ 이온은 발효기간 동안 생성되지 않았는 데 이는 혐기조건에서 유기태 질소는 대부분 암모늄태 질소 로 변환되고 질산태 질소는 거의 생성되지 않았기 때문으로 사료된다. $\mathrm{P}_{2} \mathrm{O}_{5}$ 농도는 제조 후 10 일까지 급격히 증가하며 이후 무첨가 액비를 제외하고 미생물 종류에 상관없이 약 $1 \%$ 로 유지되었다. Choi et al. (2008)은 유기자원의 유기태 질소를 빠른 시간 내에 효과적으로 분해하는 미생물의 선발 이 중요하다고 보고하였다.

건조효모 첨가량에 따른 액비 특성 비교 웃거름으 로 사용할 유기액비는 질소원 공급이 가장 중요하므로 발 효 후 $\mathrm{NH}_{4}-\mathrm{N}$ 이온 농도가 가장 높았던 건조효모를 발효 미생물원으로 선발하여 건조효모 첨가량에 따른 변화를 살펴 보았다. 효모는 아주 낮은 $\mathrm{pH}$ 나 온도 및 낮은 수분 활성도에서도 잘 증식되며 매우 혐기적인 조건에서도 증
식을 유지하거나 발효를 일으키고 염분이나 유기산 또는 당의 농도가 높거나 유기성 고형분을 포함하는 남은 음식 물의 발효에 효율적으로 이용할 수 있다는 장점이 있으며 (Lee et al., 2000), Kim et al. (2008)은 유산균과 효모균 을 함유하는 액비가 잔디의 뿌리길이, 지하부와 지상부 생 육 및 잔디의 $\mathrm{T} / \mathrm{R}$ 율을 향상에 효과가 있다고 확인 된 바 있다. 발효 미생물로 선발된 건조효모 첨가량에 따른 액비 의 $\mathrm{pH}, \mathrm{EC}$, 무기태질소, 인산 농도 변화는 Fig. 2 와 같았 다. $\mathrm{pH}$ 는 첨가량에 상관없이 액비제조 30 일차까지 낮아졌 다가 이후 증가하는 경향을 나타내며, 건조효모 $3 \%$ 첨가 구의 $\mathrm{pH}$ 가 다른 첨가구에 비해 낮았다. 액비제조 직후 $\mathrm{EC}$ 는 건조 효모 첨가량 $0 \%, 1 \%, 2 \%$, 및 $3 \%$ 에서 각각 4.2 , $3.8,5.1,4.6 \mathrm{dS} \mathrm{m}^{-1}$ 이었으며 시간이 경과함에 따라 증가 하여 90 일차에 각각 $10.2,11.6,12.2,12.3 \mathrm{dS} \mathrm{m}^{-1}$ 이었다. 건조효모 첨가구의 $\mathrm{EC}$ 는 무첨가구에 비해 높으며 건조효 모 첨가량에 따른 차이는 없었다. $\mathrm{NH}_{4}-\mathrm{N}$ 함량은 시간이 경과함에 따라 건조효모 첨가량이 많을수록 다소 증가하 는 경향이었으며 $3 \%$ 첨가에서 초기 $42.7 \mathrm{mg} \mathrm{L}^{-1}$ 에서 $2,700 \mathrm{mg} \mathrm{L}^{-1}$ 로 증가하였다. 인산 함량은 첨가량에 무관 하게 제조 60 일차까지 증가하다가 이후 감소하는 경향을 나타냈다. 액비 제조 시 발효 미생물의 첨가량에 대한 구 체적인 연구 결과는 없다. 또한 농가에서 액비 제조 시 첨 가량에 대한 기준 없이 임의대로 사용하고 있으며 적정 미 생물 첨가량에 대한 사용범위가 정해지지 않는다면 액비 

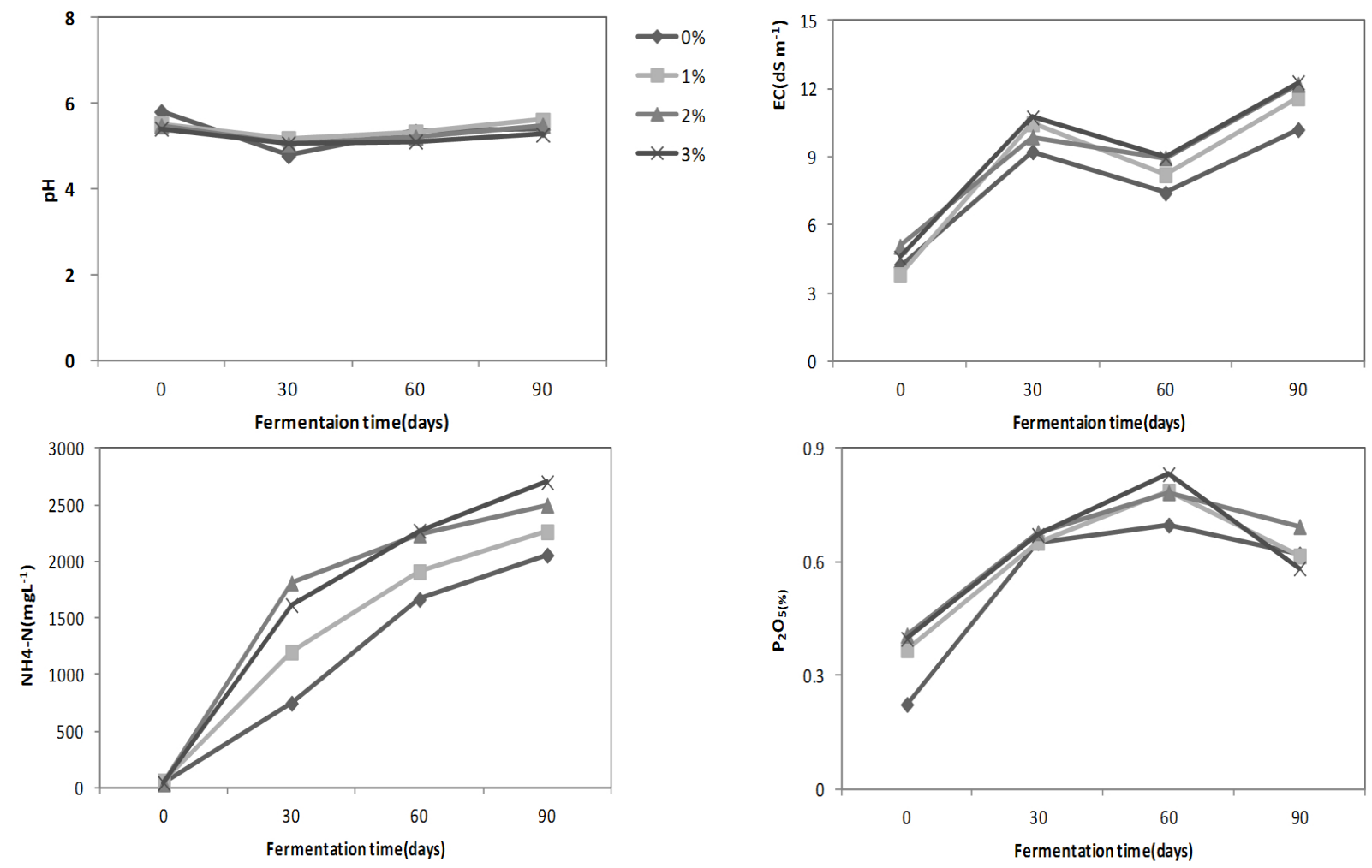

Fig. 2. Change of $\mathrm{pH}, \mathrm{EC}, \mathrm{NH}_{4}-\mathrm{N}$ and $\mathrm{P}_{2} \mathrm{O}_{5}$ contents of liquid fertilizers as affected by the ratio of dried yeast.
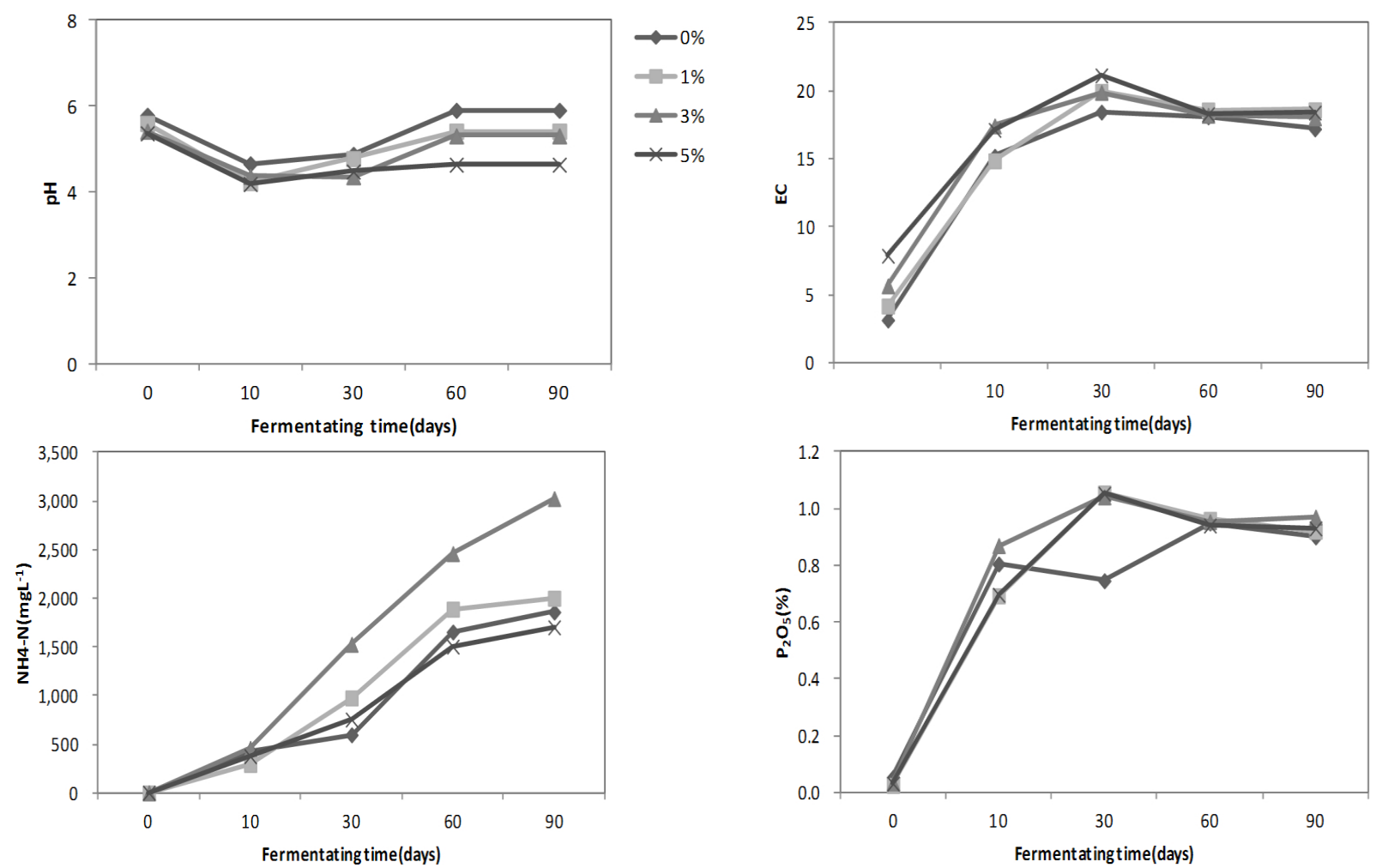

Fig. 3. Change of $\mathrm{pH}, \mathrm{EC}, \mathrm{NH}_{4}-\mathrm{N}$ and $\mathrm{P}_{2} \mathrm{O}_{5}$ contents of liquid fertilizers as affected by the ratio of Molasses.

제조비용 증가 요인이 될 수 있다. 본 연구에서는 건조효 모를 첨가할수록 $\mathrm{NH}_{4}-\mathrm{N}$ 함량이 증가하는 결과를 얻었으 며 적정 첨가량을 결정하기 위해서는 건조효모 $3 \%$ 이상 첨
가한 실험이 추가적으로 시행하여 비교한 결과가 필요할 것으로 사료된다. 
당밀 첨가량에 따른 액비 특성 비교 액비 제조 시 당밀은 미생물의 에너지원으로 미생물의 발육을 도와 액비 의 발효과정을 촉진하는 역할을 한다. 참깻묵과 쌀겨 발효 과정에 적정한 당밀 첨가량을 결정하기 위하여 당밀 첨가량 에 따른 액비의 $\mathrm{pH} . \mathrm{EC}$, 무기태질소, 인산 농도 변화를 조 사한 결과 Fig. 3과 같았다. $\mathrm{pH}$ 는 당밀 첨가 수준이 증가할 수록 낮아지는 경향을 나타내며 당밀 $5 \%$ 를 첨가하였을 때 가장 낮았다. 이는 미생물들이 당밀을 이용하여 증식함에 따라 밀도가 증가하고 그들이 생성하는 2 차 산물들이 액비 의 $\mathrm{pH}$ 를 낮아지게 한 결과라고 생각된다. $\mathrm{EC}$ 는 제조 30 일 까지 증가하다가 이후 큰 변화가 없었으며 당밀 첨가량에 따른 차이는 보이지 않았다. $\mathrm{NH}_{4}-\mathrm{N}$ 함량은 당밀 $3 \%$ 첨가 하였을 때 초기 $2.6 \mathrm{mg} \mathrm{L}^{-1}$ 에서 90 일 후 $3,025 \mathrm{mg} \mathrm{L}^{-1}$ 로 증 가하였으며 $0 \%, 1 \%$, 그리고 $5 \%$ 에서는 차이가 거의 없었다. 인산 함량은 제조 60 일차까지 증가하다가 감소하였으며 첨 가량에 따른 차이는 없었다. 사일리지 제조 시 발효과정을 촉진시키기 위하여 당밀을 사용할 경우 첨가량이 높을수록 $\mathrm{pH}$ 가 낮아지고 총미생물수가 적어지는 것으로 알려져 있다 (Jang et al., 2008). 액비의 $\mathrm{pH}$ 가 낮으면 곰팡이 등 부패를 일으키는 미생물이 저하되는 긍정적인 효과도 있지만 본 연 구에서는 질소 공급을 위한 웃거름용 액비 제조에 맞게 당 밀 첨가량은 무기태 질소의 농도가 높은 $3 \%$ 가 적합한 것으 로 판단하였다.

\section{Conclusion}

본 연구는 참깻묵과 쌀겨를 이용한 유기 액비 제조 시 발 효미생물 및 당밀의 첨가량에 따른 액비의 무기성분의 특성 변화를 조사하기 위해 수행하였다. 액비 제조 시 적절한 발 효 미생물을 선발하기 위하여 막걸리, 요구르트, 건조효모, 부엽토를 첨가하여 90 일간 발효과정을 거쳤다. $\mathrm{pH}$ 는 막걸 리 첨가구를 제외한 모든 미생물 첨가구에서 낮아졌다가 증 가하는 경향이었다. $\mathrm{EC}$ 는 제조 후 10 일차까지 급격히 증가 하다가 건조효모는 60 일, 다른 미생물 첨가구들은 30 일 이 후에는 변화가 없었다. $\mathrm{NH}_{4}-\mathrm{N}$ 농도는 발효가 진행될수록 증가하는 경향이었으며 건조효모 > 요구르트 > 막걸리 > 무 첨가 > 부엽토 첨가 순으로 높았다. $\mathrm{P}_{2} \mathrm{O}_{5}$ 농도는 제조 후 10 일까지 급격히 증가하며 이후 무첨가를 제외하고 미생물 종 류에 상관없이 약 $1 \%$ 로 유지되었다. 선발된 건조효모의 첨 가량에 따른 액비의 특성은 $\mathrm{pH}$ 의 경우 첨가량에 상관없이 액비제조 30 일차까지 낮아졌다가 이후 증가하였으며 건조 효모 $3 \%$ 첨가구에서 가장 낮았다. $\mathrm{EC}$ 는 시간이 경과함에 따라 증가하였으며 첨가량에 따른 차이는 없었다. $\mathrm{NH}_{4}-\mathrm{N}$ 함량은 시간이 경과함에 따라 건조효모 첨가량이 많을수록 증가하는 경향이었다. 당밀 첨가량에 따른 액비의 특성은 $\mathrm{pH}$ 의 경우 당밀 첨가 수준이 증가할수록 낮아지는 경향을
나타내며 당밀 $5 \%$ 첨가구가 가장 낮았다. $\mathrm{EC}$ 와 인산농도는 당밀 첨가량에 따른 차이가 없었으며, $\mathrm{NH}_{4}-\mathrm{N}$ 함량은 당밀 을 $3 \%$ 첨가 하였을 때 초기 $2.6 \mathrm{mg} \mathrm{L}^{-1}$ 에서 90 일 후 3025 $\mathrm{mg} \mathrm{L} \mathrm{L}^{-1}$ 로 가장 높았다.

\section{Acknowledgement}

본 연구는 농촌진흥청 국립농업과학원 농업과학기술 연 구개발사업 (과제번호: PJ008560022013)의 지원에 의해 이 루어진 것임.

\section{References}

An, N.H., Y.K. Kim, Y. Lee, H.J. Jee, J.H. Park, S.J. Hong, and E.J. Han. 2011. Changes in chemical properties and microbial population of farm-made organic liquid fertilizer during fermenting process. J. Kor. Org. Agr. 19:417-425.

Choi, D.H., J.K. Sung, S.M. Lee, Y.H. Lee, J.M. Kim, J.A. Jung, and B. H. Song. 2008. Selection of useful organic materials as an additional fertilizer for organic red-pepper production and the application effect. Korean J. Soil Sci. Fert. 41:153-157.

Elad, Y. and D. Shtienberg. 1994. Effect of compost water extracts on grey mould (Botrytis cinerea). Crop protection 13:109-114.

Jang, S.H., H.M. Oh, S.B. Kim, C.H. Cho, N.S. Park, B.D. Lee, H.S. Lee, and S.K. Lee. 2011. Effects of molasses and Phellinus linteus meal addition on the quality of Korean herbal medicine meal silage. J. Kor. Grassl. Forage Sci. 31:431-440. Jeon, W.T., H.M. Park, C.Y. Park, K.D. Park, Y.S. Cho, E.S. Yun, and U.G. Kang. 2003. Effect of liquid pig manure application on the rice growth and environment on paddy soil. J. Kor. Soil Sci. Fert. 36:333-343.

Jeong, K.H., T.I. Kim, K.C. Choi, J.D. Han, and W.H. Kim. 1997. Change of compost properties during aerobic composting of poultry manure. Kor. J. Anim. Sci. 39:731-738.

Joo, S.J., S.M. Shon, and J.H. Kim. 2001. Development of organic liquid fertilizer for leaf vegetable under greenhouse. J. Kor. Org. Agr. 9:83-99.

Jung, K.Y., N.J. Cho, and Y.G. Jeomg. 1998. Composition of liquid composting efficiency using liquid pig manure in different condition. Kor. J. Environ. Agr. 17:301-306.

Kai, H., T. Ueda. and M. Sakaguchi. 1990. Antimicrobial activity of bark-compost extracts. Soil Biol. Biochem. 2:983-986.

Kim, M.C., D.J. Choi, and S.T. Song. 2001. Effect of swine liquid manure and phosphorus fertilizer application level on dry matter yield and $\mathrm{N}$ and $\mathrm{P}$ uptake of italian ryegrass. Anim. Sci. \& Technol. 43:973-980.

Kim. Y.S., S.K. Ham, T.S. Kim, and H.S. Jeong. 2008. Effect of liquid fertilizer containing medium Lactobacillus confusa and Pichia anomala on growth in creeping bentgrass. Kor. Turfgrass Sci. 22:185-196. 
Lee, K.Y., S.J. Yu, and S.Y. Yu. 2000. Aerobic liquid fermentation of food wastes by using yeast. J. of KOWREC. 8:147-152.

Lee, J.T., I.J. Ha, H.D. kim, J.S. Moon, W.I. Kim, and W.D. Song. 2006. Effect of liquid pig manure on growth, nutrient uptake of onion, and chemical properties in soil. Kor. J. Hort. Sci. Technol. 24:148-156.

Lee, J.T., I.J. Ha, J.S. Moon, and W.D. Song. 2007. Comparison of liquefying efficiency of mixed organic fertilizer as affected by aeration time and the ratio of organic fertilizer to water. Korean J. Soil Sci. Fert. 40:156-163.

Lee, G.J., J.O. Jeon, J.H. Park, S.Y. Nam, and T.J. Kim. 2011. The manufacturing characteristics of organic liquid fertilizer with poultry manure, soybean meal, and rich bran. J. Kor. Org. Agr. 19:577-587.

Park, B.K., J.S. Lee, N.J. Cho, and K.Y. Jung. 2001. Effect of liquid pig manure on growth of rice and infiltration water quality. J. Kor. Soil Sci. Fert. 34:153-157.

RDA. 2000. Methods for chemical analysis of soil and plant. National Institute of Agricultural Science and Technology. RDA. Suwon. Korea.

RDA. 2010. Soil and nutrient management for organic farm land. National Institute of Agricultural Science and Technology. RDA. Suwon. Korea. 